\title{
Legal Adult
}

National Cancer Institute

\section{Source}

National Cancer Institute. Legal Adult. NCI Thesaurus. Code C52678.

A person of legal age to consent to a procedure as specifed by local regulation. 